\title{
Review Paper on Experimental and Simulation of Single Point Cutting Tool with Taguchi Method
}

\author{
SMITH BATHAM \\ Research Scholar, Mechanical Department, BM College of technology T, Indore, College \\ Prof. Purushottam Kumar Sahu \\ Assistant Professor, Department, of Mechanical, BM College, of technology, Indore
}

\begin{abstract}
The experimental results reveal that the most factors liable for increasing cutting temperature square measure cutting speed (v) and depth of cut (d) respectively. Various researches are undertaken in measuring the temperatures generated during cutting operations. Investigators created attempt to live these cutting temperatures with varied techniques throughout machining.. Single point cutting tool has been solid modelled by using SOLIDWORKS 2013 and Finite Element Analysis carried out by using ANSYS Workbench 15. By varied parameters the result of these on temperature are compared with the experimental results and FEA results.

Keywords : Turning, Single point cutting tool, ANOVA, Taguchi, FEM, explicit dynamics, Single Point Cutting Tool,

Keywords: China insurance industry, Foreign fund, Challenge

DOI: $10.7176 /$ IEL/10-1-04
\end{abstract}

Publication date: January $31^{\text {st }} 2020$

\section{I.INTRODUCTION}

Turning is a material removal process, used to create rotational parts that have a many features, such as holes, grooves, tapers, threads, various diameter steps by cutting the unwanted material. It involves with high stress and strain that should be noted to enhance all of the method. The geometry of single point cutting tool mainly depends on the tool material and the work piece material. In single point cutting tool, the most important angles are the rake angles, end relief and side relief angles. Due to effects of the back rake angle the tool shear on work material and form the chip [3]. The rake angle is normally chosen for this study as to see the geometrical effects on turning process. The cutting tools area unit used as a rigid body and it move horizontally with the variable speed into the work piece. It also set a suitable cutting condition like cutting velocity, and depth of cut. The cutting velocity, feed rate and depth of cut are from the three dimensions of the turning process and their products are used to obtain material removal rate. Machining Operations area unit among the foremost versatile and correct producing processes in terms of its capability to provide various and complicated geometric options. This chapter takes its specialize in the machining processes utilizing sharp cutting tools to get rid of materials from the piece of work by shear deformation. The main principle of those processes is providing the relative motions between the cutlery and therefore the piece of work, which is accomplished through machine tools. The machine tools area unit mentioned and categorized supported the utilized cutting tools: single-point cutting tools, multi point cutting tools, or grinding wheels. Drives and controls area unit accountable to severally offer and regulate the motions of the machine parts. Thus, industrial styles and technologies of spindle drives and feed drives, as well as numerical controls, are described in this chapter. Each of those styles has penetrated today's producing floor transfer bound superiority as compared to the standard machine tools. This chapter discusses necessary characteristics of a number of of those rising machine styles, namely, industrial robots, parallel and hybrid kinematic machine tools, and reconfigurable machine tools.

\section{LITERATURE REVIEW}

The purpose of this chapter is to produce a review of past analysis efforts associated with single purpose cutting implement and finite part analysis. A review of other research studies is also provided. The review is done to provide insight to how past research efforts have laid the groundwork for subsequent studies, including the present research effort. The review is careful so the current effort is often properly tailored to add to the current body of literature still on justify the scope and direction of the present effort.

Stephenson [1] Researcher recommended that the temperature distribution within the tool may well be obtained by using data concerning the changes within the hardness and microstructure of the steel tool. It is calibrate the hardness of the tool with respect to the temperature and time of heating and samples of structural changes at corresponding temperatures. These ways allow activity of temperatures to an accuracy of $\pm 250 \mathrm{C}$ at intervals the heat affected region.

Miller et al [2] Researcher recommended other technique of Experimental techniques using trendy, digital infrared imaging and successfully applied them during this study to gather cutting tool temperature distributions from 
orthogonal machining operations.

ABHANG L.B [3] worked to live the tool-chip interface temperature through an experiment throughout turning of EN-31 steel alloy with wolfram inorganic compound inserts employing a tool-work thermometer technique. First and second order mathematical models square measure developed in terms of machining parameters by using the response surface methodology on the idea of the experimental results. The results are analyzed statistically and graphically. The metal cutting parameters thought-about square measure cutting speed, feed rate, depth of cut and power nose radius. It are often seen from the primary order model that the cutting speed, feed rate and depth of cut are the most significantly influencing parameters for the chip-tool interface temperature followed by tool nose radius. The results show that increase in cutting speed, feed rate and depth of cut will increase the cutting temperature whereas increasing nose radius reduces the cutting temperature. The recommended models of chiptool interface temperature adequately map at intervals the vary of the cutting conditions thought-about. Temperature on the chip-tool interface is very important parameters within the analysis and management of machining method. Due to the high shear and friction energies dissipated throughout a machining operation the temperature within the first and second shear zones square measure typically terribly high; hence affect the shear deformation and tool wear. Heat is generated at three different zones i.e. first shear zone, chip tool interface and therefore the tool work interface.. The results show that increase in cutting speed, feed rate and depth of cut will increase the cutting temperature whereas increasing nose radius reduces the cutting temperature. The urged models of chip-tool interface temperature adequately map among the vary of the cutting conditions thought of.

Temperature on the chip-tool interface is very important parameters within the analysis and management of machining method. Due to the high shear and friction energies dissipated throughout a machining operation the temperature within the first and second shear zones area unit sometimes terribly high, hence affect the shear deformation and tool wear. The first shear zone temperature affects the mechanical properties of the work piecechip material and temperatures at the tool-chip and tool-work piece interfaces influence tool wear at tool face and flank respectively. Therefore, it's fascinating to see the temperatures of the tool and chip interface to investigate or management the method. To measure the tool temperature at the tool chip interface several experimental strategies are developed over the past century.

S.K. Chaudhary et al. [4] Researcher Predicted cutting elongating temperatures by natural tool work thermocouple technique, when machining EN 24 steel work piece and HSS with 10\% cobalt because the cutter. The results indicated that a rise in cutting speed and feed rate resulted in a rise in tool wear and cutting zone temperature will increase with the rise within the cutting speed. While within the whole vary of feed the temperature will increase with increase in feed rate.

Federi com Aneriro et al. [5] Investigated the influence of cutting parameters (cutting speed, feed rate and depth of cut) on tool temperature, tool wear, cutting forces and surface roughness when machining hardened steel with multilayer coated carbide tools. A standard K-type of thermocouple junction inserted close to the rake face of the tool was accustomed live the interface temperatures. They ended that the temperature close to the rake face will increase considerably once the depth of cut changes from zero. 2 to $0.4 \mathrm{~mm}$.

H. Ay and Yang] [6] seven used a way with $\mathrm{K}$ thermocouple junction to investigate temperature variations in inorganic compound inserts in cutting numerous materials like copper, cast iron aluminum 6061 and AISI 1045 steel. They ascertained oscillations in temperature close to the leading edge, which were more marked for ductile materials and less in the hard -machining materials. Through observations were attributed to the chip formation and its contact with the work material.

Kashiway and Elbestawi [7] investigated the effect of cutting temperature on the integrity of machined surface. It has been shown that cutting temperature incorporates a major impact on the integrity on the machined surface. The undesirable surface tensile residual stresses were attributed to the temperature generated during machining. Therefore, dominant the generated tensile residual stresses depends on the understanding of the impact of various method parameters on the cutting temperature.

B.Findes, et al. [8] Through the studied of researcher the influence of cutting speed, feed rate and depth of cut on cutting pressures, cutting force and on cutting temperature, The results show that depth of cut has nice influence on the radial cutting pressure and on cutting force.

W. Grzesik et al. [9] Researcher work related finite element solution simulation model thus on get numerical solutions of the cutting forces, specific cutting energy and adequate temperatures occurring at utterly different points through the chip/tool contact region and also the coating/substrate boundary for a spread of coated tool materials and outlined cutting conditions. Results showing however the tool chip surface friction influences the temperature distribution fields because the result of mistreatment coated tools area unit the most and novel findings of this paper. The various thermal simulation results obtained were compared with the measurements of the common surface temperature and mentioned in terms of varied literature information.

The finite part simulations performed demonstrate the existence and localization of the secondary shear zone. A good agreement was achieved, particularly for uncoated and three-layer coated tools, between predicted and experimental values of cutting temperatures. It was documented that coatings cause that area unites with the most 
temperatures are localized close to the chip and work piece. In consequence, the most interface temperature exists within the neighbourhood of the leading edge. i.e. in the first part of the tool-chip contact. Also the substrate is distinctly cooler as compared to uncoated tools.

Kazban Roman V. [10] through the studied of researcher the machining industry for cost reduction and increases in productivity have contributed to new interest in high-speed machining. Several model for machining exists, In machining at high speeds momentum may be giant and also the strain rates are often passing high. For these reasons a hydraulics approach to understanding high-speed, very high speed and ultra-high speed machining is attempted here.

Namely, a possible flow answer is employed to model the behavior of the fabric around a tool tip throughout machining at high speeds, i.e. greater than or equal to $100 \mathrm{~m} / \mathrm{s}$. It is rigorously argued that the potential flow answer has relevancy and might be used as a primary approximation to model the behavior of a metal throughout highspeed, very high-speed or ultra-high-speed machining events. The minimum potential flow solution is qualitatively useful in understanding mechanics of high-speed, very high-speed and ultra-high-speed machining. Interestingly, the flow answer predicts that there's a "stagnation" purpose on the rake face, not at the tool tip as is usually assumed.

A centered array of Mercury-CadmiumTellurium infrared detectors is employed to live the temperature distribution. A three-component quartz force electrical device is used in mensuration the cutting and feed forces. Measurements of the cutting and feed forces contributed to the flexibility to prove the steady-state conditions moreover on estimate the constant of

Friction on the tool rake face in conjunction with the partition of the thermal energy created throughout the high-speed machining method. Force measurements show that at this speed, on the higher boundary of the vary of cutting velocities for high-speed machining not high enough to be very-high speed or ultra-high speed cutting, Therefore, a study of the temperature fields generated throughout machining with a cutlery that incorporates a wear-land was performed.

Federico M. Aneriro et al. [11] Investigated the influence of cutting parameters (cutting speed, feed rate and depth of cut) on tool temperature, tool wear, cutting forces and surface roughness when machining hardened steel with multilayer coated carbide tools. A standard K-type of thermocouple junction inserted close to the rake face of the tool was wont to live the interface temperatures. They ended that the temperature close to the rake face will increase considerably once the depth of cut changes from zero. 2 to $0.4 \mathrm{~mm}$. The increase connected length between chip and rake face may well be accountable, since it grows, together with uncut chip cross-section.

S.K. Chaudhary et al. [12] expected cutting zone temperatures by natural tool work thermocouple junction technique, once machining nut twenty four steel work piece and HSS with 100 present metal because the cutlery. The results indicated that a rise in cutting speed and feed rate resulted in a rise in tool wear and cutting zone temperature will increase with the rise within the cutting speed. While within the whole vary of feed the temperature will increase with increase in feed rate.

Huda et al [13] developed a way for mensuration temperature at the interface between a cutlery and a chip victimization two-color thermometer with amalgamated fiber mechanical device for the temperature with measurement of the tool-chip interface in dry and wet turning.

H.Ay and principle [14] Researcher suggested to technique with thermocouple to calculate temperature variations in carbide inserts in cutting various materials such as copper, cast iron aluminum and steel. They determined oscillations in temperature close to the leading edge, which were more than for ductile materials and less in the hard machining materials.

Kashiway and Elbestawi [15] investigated the effect of cutting temperature on the integrity of machined surface. It has been shown that cutting temperature incorporates a major result on the integrity on the machined surface. The undesirable surface tensile residual stresses were attributed to the temperature generated during machining. Therefore, controlling the generated tensile residual stresses depends on the understanding of the result of various method parameters on the cutting temperature.

\section{CONCLUSION OF RESEARCH REVIEW:}

As the single point cutting tool is one amongst the key a part of machining method, to extend tool efficiency and performance along with its life.

1. It is terribly necessary to analysis it by thermally and statically.

2. In this study metal cutting analysis is performed using Single point cutting tool.

3. Numerical simulation is performed on ANSYS explicit software.

4. All experiments are designed according to taguchi methods. Signal to noise ratio analysis is performed in this study and the final conclusion from this test is that depth of cut and cutting speed more significant factor

\section{OBJECTIVES OF THE STUDY:}

Heat is a parameter which strongly influences the tool performance during the operation. So the machining can be 
improved by the knowledge of temperature distribution on the tool. Thus the main objectives of this project are as follows:

1. Study and comparison of temperature distribution on a single point cutting tool of different materials at various machining parameters.

2. Modelling and finite element analysis of single point cutting tool.

3. Comparison of experimental data with finite element analysis data for the tool.

\section{REFERENCES}

[1] D.A. Stephenson, Tool -work thermocoupletemperature measurements: theory and implementation issues, Proceedings of winter Annual meeting of ASME, Anaheim CA. pp-18-95. November (1992).

[2] Miller Mark R., Mulholland George, Anderson Charles, Journal of Manufacturing Science and Engineering, vol. 125(2003), pp. 667-673

[3]. L.B.ABHANG* and M. HAMEEDULLAHDepartment of Mechanical Engineering, Aligarh Muslim University, Aligarh, India "Chip-Tool Interface Temperature Prediction Model for Turning Process" 2010.

[4]. S.K Choudhary, G.Bartarya, Role of temperature and surface finish in predicting tool wear using neural network and design of experiments.Int. J.of machine tools and manufacture,43, (2003), 747-753.

[5]. Federico M. Aheiro Reginalot, Coelho, Lincdnc, Brandao, Turning hardened steel using coated carbide at high cutting speeds. J.of the Braz.soc.of Mech.sci.and Engg.(2008), vol.xxx.no.2 1109

[6]. H.Ay, W.J Yang, Heat transfer and life of metal cutting tools in turning, Int, J. Heat and mass transfer,41,(1998),613-623.

[7]. Kishawy,H.A. Elbestawi, M.A, Effect of edge preparation and cutting speed on surface integrity of die materials in hard machining, ASME Int.Eng. Congr, Exp. Manf.sci, Techno, (1998), 269-276.

[8]. B.Fnides, M.A. Yallese, H, Aouici, Hard turning of hot work steel AISI H11: Evaluation of cutting pressure, resulting force and temperature, ISSN1392-1207, Mecanika, 2008.Nr.4 (72).

[9] Grzesik, W, Experimental investigation of the cutting temperature when turning with coated Index able inserts .Int.J, of Machine tools and manufacture, 39 pp 355-369,(1999).

[10] Roman V. Kazban, B.S.,M.S. University of Notre Dame Indiana effect of tool parameters on residual stress and temperature generation in high speed machining of aluminum November 2005.

[11] Federico M. Aheiro Reginalot, Coelho, Lincdnc, Brandao, Turning hardened steel using coated carbide at high cutting speeds. J.of the Braz. soc. of Mech. sci. and Engg., vol.xxx. no. 2 1109, (2008). [13] Sullivan D.O., Cotterell M., Journal of Material Processing Technology, vol. 118(2001), pp. 301-308 